\title{
Pegylated liposomal formulation of doxorubicin overcomes drug resistance in a genetically engineered mouse model of breast cancer
}

Authors: András Füredii ${ }^{1,2}$, Kornélia Szebényi ${ }^{2}$, Szilárd Tóth ${ }^{1}$, Mihály Cserepes ${ }^{1,3}$, Lilla Hámori ${ }^{1}$, Veronika Nagy ${ }^{1}$, Edina Karai ${ }^{1,4}$, Péter Vajdovich ${ }^{4}$, Tímea Imre $^{1}$, Pál Szabó ${ }^{1}$, Dávid Szüts ${ }^{1}$, József Tóvári ${ }^{3}$, Gergely Szakács ${ }^{1,2 *}$

\section{Affiliations:}

${ }^{1}$ Institute of Enzymology, Research Centre for Natural Sciences, Hungarian Academy of Sciences, P.O.B. 286, Budapest 1519, Hungary

${ }^{2}$ Institute of Cancer Research, Medical University Vienna, Vienna, Austria

${ }^{3}$ Department of Experimental Pharmacology, National Institute of Oncology, Budapest, Hungary

${ }^{4}$ Department of Clinical Pathology and Oncology, Faculty of Veterinary Science, Szent István University, Budapest, Hungary

*Corresponding author: P.O.B. 286, Budapest 1519, Hungary, szakacs.gergely@ttk.mta.hu, szakacs.gergely@meduniwien.ac.at 


\begin{abstract}
Success of cancer treatment is often hampered by the emergence of multidrug resistance (MDR) mediated by P-glycoprotein (ABCB1/Pgp). Doxorubicin (DOX) is recognized by Pgp and therefore it can induce therapy resistance in breast cancer patients. In this study our aim was to evaluate the susceptibility of the pegylated liposomal formulation of doxorubicin (PLD/Doxil®/Caelyx $\left.{ }^{\circledR}\right)$ to MDR. We show that cells selected to be resistant to DOX are crossresistant to PLD and PLD is also ineffective in an allograft model of doxorubicin-resistant mouse B-cell leukemia. In contrast, PLD was far more efficient than DOX as reflected by a significant increase of both relapse-free and overall survival of $\mathrm{Brcal}^{--} ; \mathrm{p}^{-1-}$ mammary tumor bearing mice. Increased survival could be explained by the delayed onset of drug resistance. Consistent with the higher Pgp levels needed to confer resistance, PLD administration was able to overcome doxorubicin insensitivity of the mouse mammary tumors. Our results indicate that the favorable pharmacokinetics achieved with PLD can effectively overcome Pgp-mediated resistance, suggesting that PLD therapy could be a promising strategy for the treatment of therapy-resistant breast cancer patients.
\end{abstract}

Keywords: breast cancer, multidrug resistance, pegylated liposomal doxorubicin, P-glycoprotein, genetically engineered mouse model

\title{
Introduction
}

Chemotherapy remains the principal therapeutic modality in cancer treatment. Despite recent successes, such as the discovery of the BCR-ABL tyrosine kinase inhibitors in chronic myeloid leukemia (CML), all-trans retinoic acid (ATRA) in acute promyelocytic leukemia (APL) 
and other advances in testicular cancer, pediatric leukemias and Hodgkin's lymphomas, which have demonstrated striking effects on patients survival [1], resistance and relapse remains a major obstacle [2].

Breast cancer is the most common malignancy in women. Approximately $60 \%$ of the breast cancer patients diagnosed at an early stage of the disease receive chemotherapy, but only a minor fraction of patients actually benefit from it [3]. 30\% of women diagnosed with early stage breast cancer will progress to metastatic disease where there are only few treatment options [4]. Response to anthracycline- or taxane-based treatment regimens is overall weak and not long-lasting [5]. A study concluded that $50-70 \%$ of relapsing tumors from surgically removed adenocarcinomas were already drug resistant [6].

Resistance to anticancer agents is based on several mechanisms. Cancer cells can downregulate the drug target, tune down pathways leading to apoptosis, upregulate DNA repair mechanisms or increase the metabolism of drug molecules [7]. One of the most frequent and most investigated mechanisms of cellular drug resistance relies on the active efflux of the chemotherapeutical compounds from the cells. P-glycoprotein (ABCB1/Pgp), a member of the ATP Binding Cassette (ABC) transporter family was shown to extrude numerous, structurally unrelated chemotherapeutic drugs from resistant cancer cells [8]. There is ample evidence to prove the link between the activity of Pgp and clinical anticancer drug resistance. Pgp expression is an independent prognostic factor in acute myeloid leukemia (AML) $[9,10]$ and acute nonlymphoblastic leukemia (ANLL) [11]. Pgp function in tumor cells shows negative correlation with response to the treatment and reliably predicts therapy response in AML [12].

Recently, genetically engineered mouse models (GEMMs) have been introduced to the study of drug resistance mechanisms. GEMMs closely mimic cancer in human patients and 
therefore offer a unique opportunity to study the evolution of drug resistance. In particular, conditional deletion of the Brca1 and p53 genes was shown to give rise to mammary carcinomas that mimic many aspects of the human disease [13]. In contrast to the xenograft models, these spontaneous tumors become drug resistant as a result of the treatment [14]. Like most human cancers, Brcal ${ }^{-/} ; \mathrm{p5}^{-/-}$tumors show initial sensitivity to doxorubicin, topotecan, cisplatin [15], and the poly(ADP-ribose)-polymerase (PARP) inhibitor olaparib, which induce synthetic lethality in BRCA1- or BRCA2-deficient cells [16]. However, the tumors always acquire resistance to docetaxel, doxorubicin, topotecan or olaparib [17,18], based on the increased expression of the Abcb1 or Abcg2 genes. Inhibition of ABCB1 using tariquidar successfully reversed drug resistance [19], and the relevance of the efflux-based drug resistance was also confirmed in $\mathrm{ABC}$ transporter-deficient tumors [18].

While there is a constant need for finding new targets, the efficacy of existing drugs could also be restored by eliminating resistance mechanisms. Unfortunately, attempts to circumvent the reduced drug accumulation by inhibiting drug efflux have failed in clinical trials, because inhibition of Pgp in cancer cells altered the pharmacokinetic properties of the coadministered cytotoxic compounds [20]. Because selective modulation of Pgp in cancer cells remains difficult to achieve, attempts to circumvent MDR rely on further strategies such as the targeting the paradoxical hypersensitivity of MDR cancer [21-24]. Another possibility is to develop drugs that bypass efflux either through the chemical modification of the cytotoxic compounds or through novel formulations of existing therapeutics [25].

Doxorubicin (DOX) is still one of the most effective chemotherapeutic agents used in lung, breast, ovarian, uterine cancers and in lymphomas and leukemias [26-28]. The pegylated liposomal formulation of doxorubicin (PLD/Doxil®/Caelyx $\left.{ }^{\circledR}\right)$ was developed to overcome 
DOX's dose limiting cardiotoxicity and myelosuppression [29]. PLD has the ability to avoid the reticuloendothelial system ("stealthness") [30], and as a result of the enhanced permeability and retention (EPR) effect, PLD is "passively" targeted to tumors [31,32]. PLD's efficacy was evaluated in several allo- and xenograft models of colon [33], breast [34], ovarian [35], lung [36], leukemia [37], lymphoma [38], bladder [39] and prostate cancer [40]. These studies have convincingly demonstrated that PLD has an equal or even better performance than DOX (reviewed in [41]). Clinical trials comparing PLD to DOX in patients with metastatic breast cancer (MBC) proved that both treatments are comparably efficient [42].

DOX is recognized by Pgp and therefore it can induce therapy resistance in breast cancer patients [43]. In this study our aim was to evaluate the susceptibility of PLD to MDR. We show that cells selected to be resistant to DOX are cross-resistant to PLD. However, in contrast to doxorubicin, PLD treatment results in a durable response of BRCA1-deficient mammary tumors, and PLD remains effective in DOX-resistant ABCB1-expressing tumors.

\section{Materials and Methods}

\section{Drugs}

Cytotoxic drugs Doxorubicin (DOX, TEVA), PEGylated liposomal Doxorubicin Caelyx ${ }^{\circledR}$ (PLD, Janssen) and Cisplatin (CDDP, Accord Healthcare) were purchased directly from the manufacturers. The compounds used in the DT40 cytotoxicity assays were purchased from Selleckchem (olaparib), Sigma-Aldrich (paclitaxel, SN-38, doxorubicin) or Accord Healthcare (PLD, 5-FU) or TEVA (etoposide). Daunorubicin was a kind gift from Dr. Gábor Mező (ELTE, Hungary). 


\section{Cell lines}

The human uterine sarcoma cell lines MES-SA and the doxorubicin selected MES-SA/Dx5 were obtained from ATCC (MES-SA: No. CRL-1976M , MES-SA/Dx5: No. CRL-1977TM). The human mammary carcinoma cell lines MCF7, T47D, MDA-MB-231, MDA-MB-468, Hs578T, BT-549, the mouse leukemic P388 and its doxorubicin selected subline P388/ADR were obtained from the National Cancer Institute's Developmental Therapeutics Program (National Institutes of Health). P388/ADR, and Dx5 cells were maintained in 800 and $500 \mathrm{nmol} / \mathrm{L}$ doxorubicin (Adriamycin), respectively. The human breast cancer and the mouse leukemia cell lines were cultured in RPMI media (Life Technologies) supplemented with $10 \%$ fetal bovine serum, $5 \mathrm{mmol} / \mathrm{L}$ glutamine, and 50 units/mL penicillin and streptomycin (Life Technologies). MES-SA and MES-SA/Dx5 cells were cultured in supplemented DMEM media (Life Technologies). The chicken DT40 B cell line was grown in RPMI-1640 medium supplemented with 7\% fetal bovine serum, 3\% chicken serum, $50 \mu \mathrm{M}$ 2-mercaptoethanol and penicillin/streptomycin. Wild-type DT40 clone18 cells [44] and a BRCA1 null mutant line [45] were used. All cell lines were cultured at $37^{\circ} \mathrm{C}, 5 \% \mathrm{CO} 2$.

\section{In vitro cytotoxicity assay}

Viability was assessed by the PrestoBlue ${ }^{\circledR}$ assay (Life Technologies), according to the manufacturer's instructions. Briefly, cells were plated in 96- or 384-well plates, treated in the given concentration range with the indicated compounds for $120 \mathrm{~h}$ or $72 \mathrm{~h}$ in case of DT40 cells. Viability of the cells was measured spectrophotometrically using an EnSpire microplate reader (Perkin Elmer). Data were normalized to untreated cells; curves were fitted by the Graph Pad Prism 5 
software using the sigmoidal dose-response model. Curve fit statistics were used to determine $\mathrm{IC}_{50}$ values.

\section{Immunohistochemistry}

Snap-frozen tissues were cut with a cryostat into $5 \mu \mathrm{m}$ sections. The tissue slices were transferred onto microscope slides and fixed with ice-cold methanol for $10 \mathrm{~min}$. Tissue sections were then washed in PBS, blocked with 3\% bovine serum in PBS (1 hr), stained with hematoxylin and eosin and then the sections were mounted with ProLong Gold (Life Technologies). Immunohistochemistry images were examined by an Eclipse TS100 microscope (Nikon).

\section{RNA isolation and RT-PCR}

Snap-frozen tumor samples were pulverized under liquid nitrogen and were homogenized in TRIzol $^{\text {TM }}$ Reagent (Life Technologies). Total RNA was isolated from tissue samples using Directzol ${ }^{\circledR}$ MiniPrep kit (Zymo Research) according to the manufacturer's guidelines. In-column DNAse I treatment was applied to prevent DNA contamination. cDNA samples were prepared from 300 ng total RNA using the Promega Reverse Transcription System Kit. The Pre-Developed TaqMan ${ }^{\circ}$ assay Actin $\beta$ (Actß) (Life Technologies) was used as endogenous control in real-time qPCR experiments; for quantifying Abcbla and Abcblb mRNA levels the respective TaqMan ${ }^{\circledR}$ primers were used. Real time PCR analyses were carried out using the StepOne ${ }^{\mathrm{TM}}$ Real-Time PCR System (Life Technologies); mRNA fold changes were determined using the $2^{-\Delta \Delta C t}$ method. Relative mRNA levels were presented as mean values \pm S.E.M. of 3 independent experiments. 


\section{Animal experiments}

All animal protocols were approved by the Hungarian Animal Health and Animal Welfare Directorate according to the EU's most recent directives. All surgical procedures were performed according to the Committee on the Care and Use of Laboratory Animals of the Council on Animal Care at the Institute of Enzymology, RCNS in Budapest, Hungary (22.1/2291/3/2010).

P388 and P388/ADR cells $\left(1 \times 10^{6} /\right.$ animal $)$ were injected into the intraperitoneal cavity of 6-8 week old male BDF1 mice and 48h later a single dose of saline, doxorubicin (3 mg/kg) or PLD (3 or 5 $\mathrm{mg} / \mathrm{kg}$ ) were administered intraperitoneally. The animals were weighted 3 times per week and monitored multiple times per day for any sign of pain. MTD was determined based on the weight loss of healthy FVB mice. Drug resistance of tumor implants was induced as described by

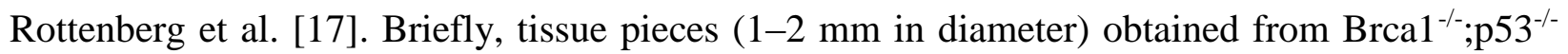
FVB mouse mammary tumors (a kind gift from Sven Rottenberg, NKI) were transplanted orthotopically into the mammary fat pad of wild type FVB mice (Harlan) under anesthesia (20 $\mathrm{mg} / \mathrm{kg}$ zolazepam, $12.5 \mathrm{mg} / \mathrm{kg}$ xylazine, $3 \mathrm{mg} / \mathrm{kg}$ butorphanol, $20 \mathrm{mg} / \mathrm{kg}$ tiletamine). The tumor size was monitored at least 3 times per week by caliper measurements after the tumors became palpable. Tumor volume was calculated using the $V=$ length $\times\left(\right.$ width $\left.^{2} / 2\right)$ formula. When the volume of the tumors reached $\sim 200 \mathrm{~mm}^{3}$, DOX and PLD treatment was initiated using the maximum tolerable dose (MTD, 5 and $8 \mathrm{mg} / \mathrm{kg}$ iv respectively). Treatments using the MTD were repeated every 10 days unless the size of the tumors decreased to $50 \%$ of its original volume. In that case treatment was repeated when the tumor relapsed to its original size. Animals were sacrificed when the tumor volume reached $\sim 2000 \mathrm{~mm}^{3}$. 
Measurement of serum and tumoral doxorubicin levels after DOX or PLD treatment

FVB mice were treated with a single dose of intravenous doxorubicin $(5 \mathrm{mg} / \mathrm{kg})$ or PLD $(8 \mathrm{mg} / \mathrm{kg})$.

Blood samples were taken before administration and after 5, 15, 30, 60, 180, 360, 1440, 2880

minutes by cardiac puncture of euthanized animals. Blood serum was separated by centrifugation at $4000 \mathrm{rpm}$ for 15 minutes at $4^{\circ} \mathrm{C}$. For the determination of tumoral doxorubicin levels tumor pieces obtained from $\mathrm{Brcal}^{--} ;{\mathrm{p} 53^{---}}^{\mathrm{FVB}}$ mouse mammary tumors were transplanted orthotopically into the mammary fat pad of wild type FVB mice. When the volume of the tumors reached $\sim 200 \mathrm{~mm}^{3}$, DOX and PLD treatment was initiated using the maximum tolerable dose (MTD, 5 and $8 \mathrm{mg} / \mathrm{kg}$ iv respectively). Animals were sacrificed after 24, 48 and 72 hours; the tumors were mechanically homogenized in phosphate-buffered saline $(\sim 200 \mathrm{mg} / \mathrm{ml})$ and subjected to acetonitrile protein precipitation. LC-MS/MS analysis was performed using a QTRAP 6500 triple quadruple - linear iontrap mass spectrometer, equipped with a Turbo V Source in electrospray mode (AB Sciex, CA, USA) and a Perkin Elmer Series 200 micro LC system (Massachusetts, USA). Chromatographic separation was achieved using an Agilent Zorbax SB C18 column $(75 \mathrm{~mm} \times 4,6 \mathrm{~mm}, 3,5 \mu \mathrm{m})$. Sample was eluted with a gradient of solvent A $(0.1 \%$ formic acid in water) and solvent B ( $0.1 \%$ formic acid in acetonitrile). Quantitation of doxorubicin was performed using multiple reaction monitoring mode (MRM) with the transitions of m/z 544 $\rightarrow 361$ (quantifier) and $\mathrm{m} / \mathrm{z} 544 \rightarrow 130$ (qualifier).

\section{Results}

\section{PLD does not overcome $A B C B 1$-mediated doxorubicin resistance in vitro}

To evaluate the effect of pegylated liposomal formulation on the in vitro toxicity of doxorubicin, we compared the toxicity of DOX and PLD in the NCI-60 breast cancer cell lines. 
Whereas DOX showed strong toxicity in all six cell lines, the $\mathrm{IC}_{50}$ values of PLD were on average 51-fold higher (Table 1). MDA-MB-468 cells were relatively more sensitive to both cisplatin and PLD, in line with the loss of PTEN expression in this cell line [46]. Next, we evaluated the susceptibility of DOX and PLD to Pgp-mediated MDR, using pairs of drug-sensitive and multidrug resistant cell lines. As expected, A431-B1, MESS-SA/Dx5 and P388/ADR cells expressing Pgp were resistant to DOX as compared to their sensitive counterparts. Pgp expression also conferred resistance to PLD, which was virtually nontoxic to A431-B1, MESS-SA/Dx5 and P388/ADR cells. Addition of the Pgp-inhibitor tariquidar restored sensitivity, proving that P-glycoprotein can protect cells against doxorubicin despite its stealth formulation (Table 1). ABCG2, another wellcharacterized multidrug transporter, did not confer resistance against PLD (Supplementary Table S1).

\begin{tabular}{|l|c|c|c|c|c|}
\hline Cell line & DOX & $\begin{array}{c}\text { DOX + } \\
\text { TQ }\end{array}$ & PLD & $\begin{array}{c}\text { PLD + } \\
\text { TQ }\end{array}$ & Cisplatin \\
\hline \hline BT-549 & 0,02 & - & 1,68 & - & 7,62 \\
\hline Hs578T & 0,08 & - & 5,65 & - & 16,93 \\
\hline MDA-MB-231 & 0,01 & - & 0,59 & - & 6,42 \\
\hline MCF-7 & 0,13 & - & 3,63 & - & 48,75 \\
\hline T47D & 0,03 & - & 1,21 & - & 10,79 \\
\hline MDA-MB-468 & 0,02 & - & 0,49 & - & 0,71 \\
\hline \hline A431 & 0,33 & - & 12,30 & - & 19,50 \\
\hline A431-B1 & 8,52 & 0,32 & $>250$ & 7,14 & 23,10 \\
\hline RR & 25,8 & & $>20,3$ & & \\
\hline MES-SA & 0,07 & - & 4,00 & - & 7,58 \\
\hline MES-SA/Dx5 & 2,88 & 0,02 & $>250$ & 0,10 & 12,52 \\
\hline RR & 41,1 & & $>62,5$ & & \\
\hline P388 & 0,00015 & - & 0,00075 & - & 0,61 \\
\hline P388/ADR & 2,04 & 0,00069 & 10,19 & 0,00230 & 1,18 \\
RR & 13600 & & 13587 & & \\
\hline
\end{tabular}

Table 1. In vitro toxicity (IC50) of DOX, PLD and Cisplatin $(\mu \mathrm{M})$ in six breast cancer cell lines (top) and in parental and Pgp-expressing MDR cells (bottom). Values represent the 
average of at least three independent experiments. RR: Resistance Ratio ( $\mathrm{IC}_{50}$ resistant cell//C 50 sensitive cell). TQ: Pgp inhibitor tariquidar.

\section{PLD is ineffective in an allograft model of doxorubicin-resistant mouse B-cell leukemia}

In real tumors, the efficacy of treatment is also influenced by extracellular factors, such as tissue distribution or the cross-talk between microenvironment and cancer cells [47]. In the next set of experiments we monitored the effect of DOX or PLD treatment on the survival of BDF1 mice bearing drug-sensitive (P388) or drug-resistant (P388/ADR) intraperitoneal ascites tumors (Fig. 1). In line with its reduced toxicity, PLD could be administered at significantly higher doses. P388 tumors responded well to DOX and PLD, which was reflected in a significant increase in the median survival (DOX: 29 days; PLD (3 mg/kg): 28 days; PLD (5 mg/kg): >63 days as compared to saline (15.5 days)), while the same treatment failed to prolong survival of mice inoculated with resistant P388/ADR cells (DOX: 12.5 days; PLD (3 mg/kg): 13 days). Whereas P388 tumors showed a dose-dependent response to PLD, the Abcb1-expressing P388/ADR tumors were completely resistant even at a higher PLD dose (PLD (5 mg/kg): 16 days). Thus, in line with the in vitro data, this particular in vivo model indicates that, despite the stealth formulation, PLD cannot be considered as an effective solution for the treatment of multidrug resistant tumors. 


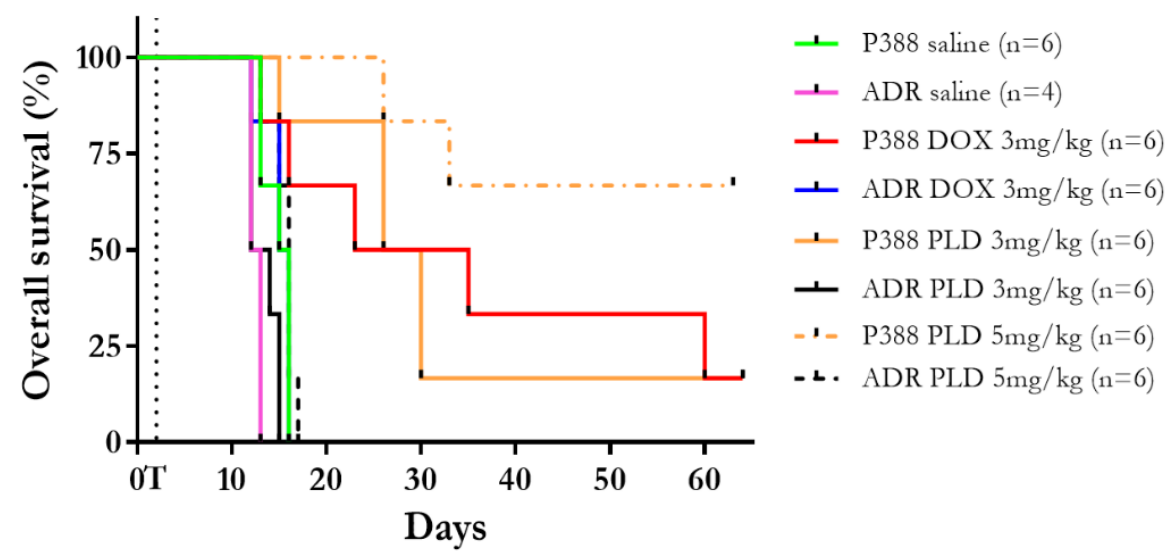

Fig. 1. DOX and PLD are ineffective in an ascites model of resistant leukemia. Drug-naive P388 or drug resistant P388/ADR tumor bearing mice were treated with saline (green and pink), 3 $\mathrm{mg} / \mathrm{kg}$ of DOX (red and blue) or PLD (orange and black) or $5 \mathrm{mg} / \mathrm{kg}$ of PLD (dashed dotted orange and black). The dotted vertical line indicates the time of treatment (T) at Day 2.

\section{PLD prolongs relapse-free and overall survival in a $\mathrm{Brcal}^{-/-} ; \mathrm{p5}^{-/-}$tumor model of hereditary mammary cancer}

To test the therapeutic value of PLD in a more relevant model, we treated mice bearing orthotopically transplanted mammary tumors obtained from $\mathrm{Brca}^{-/-} ; \mathrm{p} 53^{-/-}$mice $[17,18]$. Again, PLD could be administered at higher doses than DOX (8 mg/kg and $5 \mathrm{mg} / \mathrm{kg}$, respectively). Whereas saline-treated mice had to be sacrificed within 12 days, treatment with the maximum tolerated dose (MTD) of doxorubicin increased the median survival of mice to 49.5 days. As compared to doxorubicin, treatment with the MTD of PLD resulted in a 6-fold increase in median relapse-free survival, and a 3-fold increase in median overall survival (9 vs 56 days and 49.5 vs 151.5 days, respectively) with the longest survival of 247 days (Fig. 2A, B). Growth kinetics of individual tumors revealed fundamental differences between the DOX and PLD groups (Fig. 2C 
and 2D). Saline-treated animals had to be sacrificed by day 12 because the tumor volume reached the limit of $\sim 2000 \mathrm{~mm}^{3}$ (Fig. 2C, upper left graph). In some tumors, treatment with the MTD of DOX resulted in an initial response, but eventually all tumors relapsed and became resistant to therapy within 60 days (Fig. 2C). In contrast, 8 of the 10 tumors treated with the MTD of PLD were efficiently contained and only two tumors became refractory to treatment (PLD 1 and 7) (Fig. 2D). However, responding tumors could not be completely eradicated before the mice had to be euthanized due to the cumulating side effects of the PLD treatment. Immunohistochemical characterization of tumor sections from the 3 treatment groups revealed increased necrosis in the PLD treated tumors. There were no further morphological or structural differences, nor a change in the number of infiltrating immune cells, suggesting that the superior efficacy of PLD is not due to an elevated immune response (Supplementary Fig. S1). 


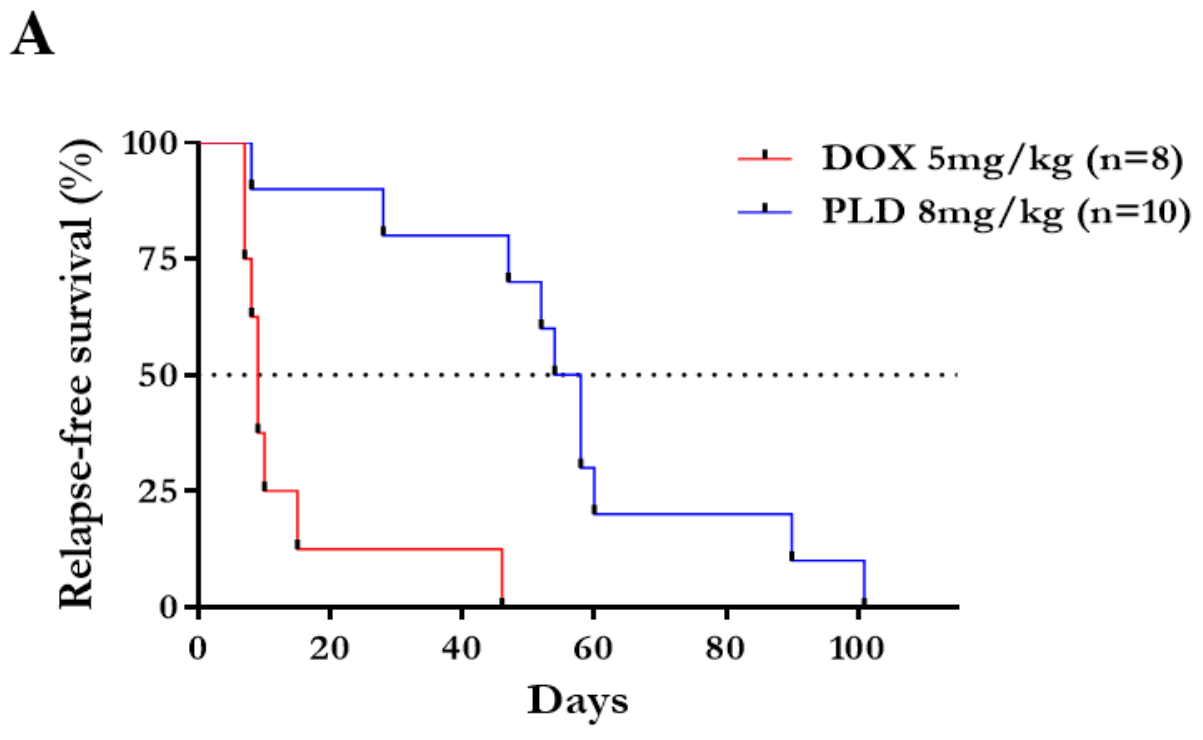

B

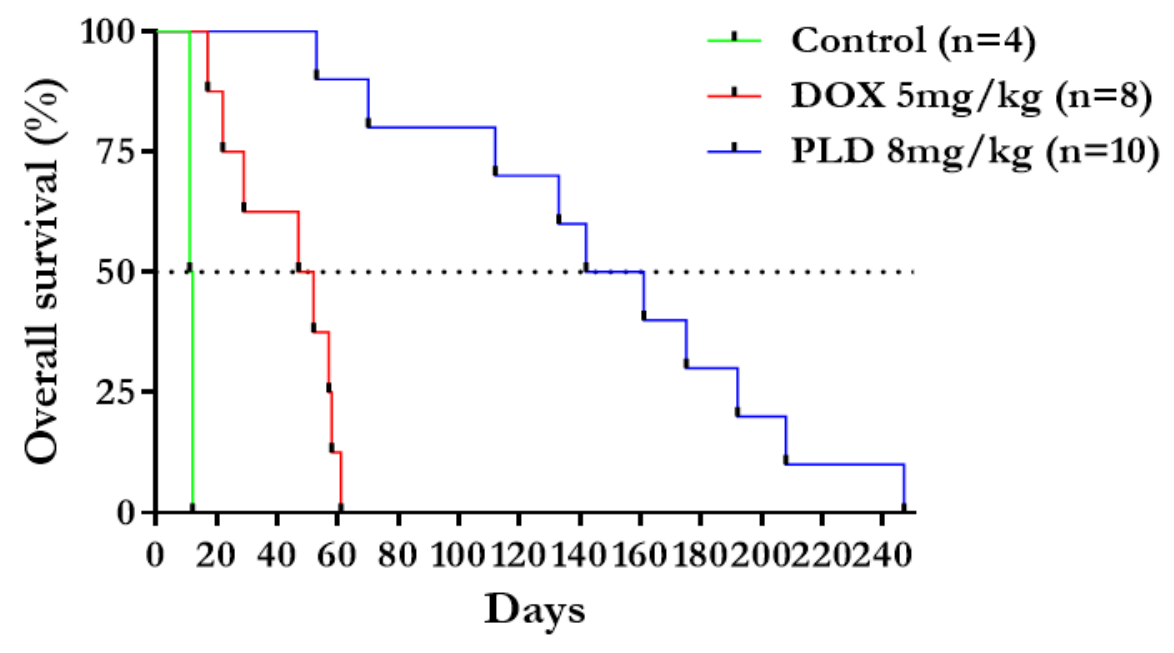

Fig. 2. PLD is superior to DOX in a clinically relevant mouse model of breast cancer. A. Relapse-free and B. Overall survival of DOX (5 mg/kg iv) and PLD ( $8 \mathrm{mg} / \mathrm{kg}$ iv) treated groups. 
C
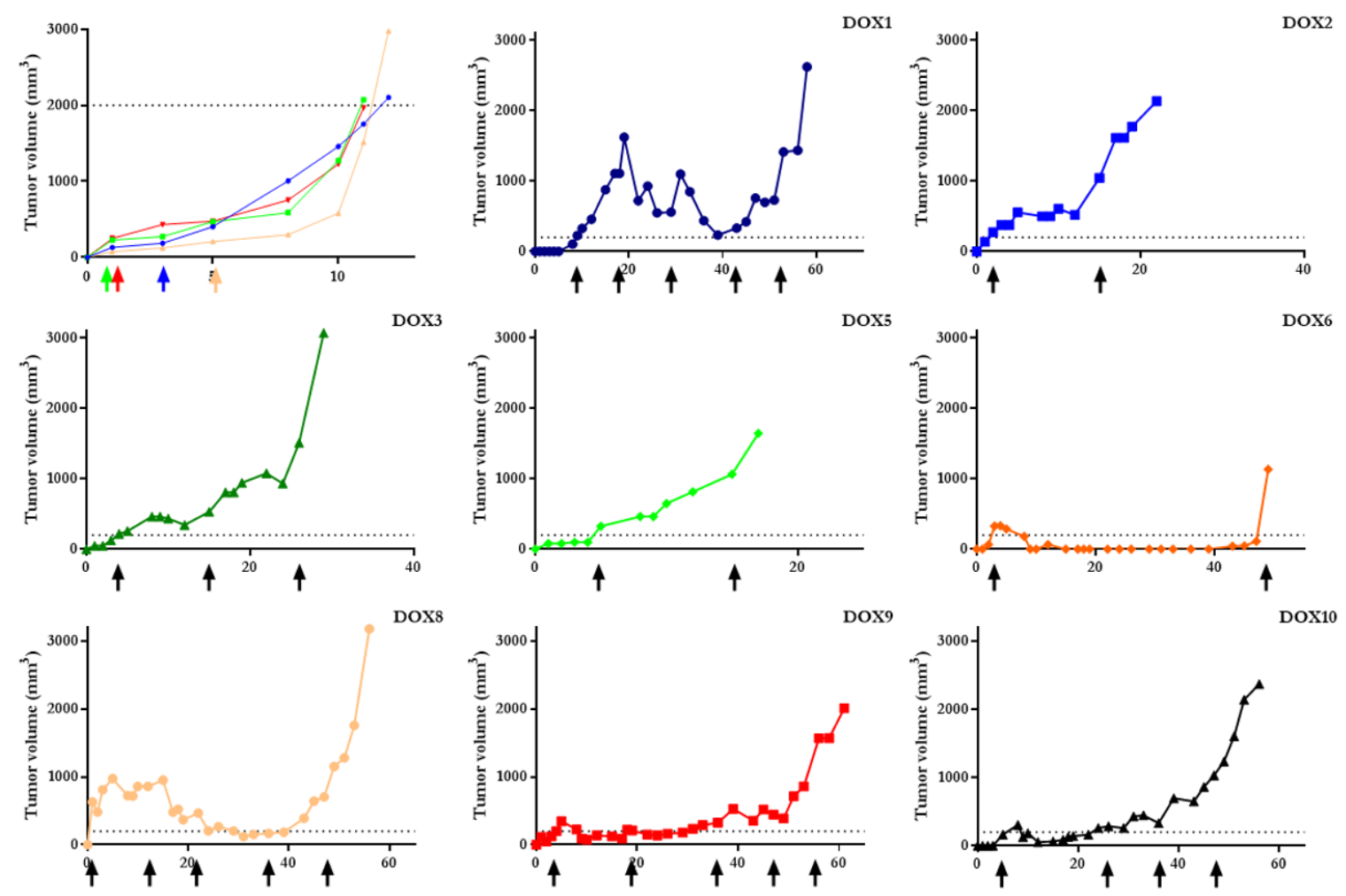

Fig. 2C. Growth kinetics of saline (upper left panel), DOX (DOX1-10) and D. PLD (PLD1-10) treated individual tumors. Arrows indicate treatment. 

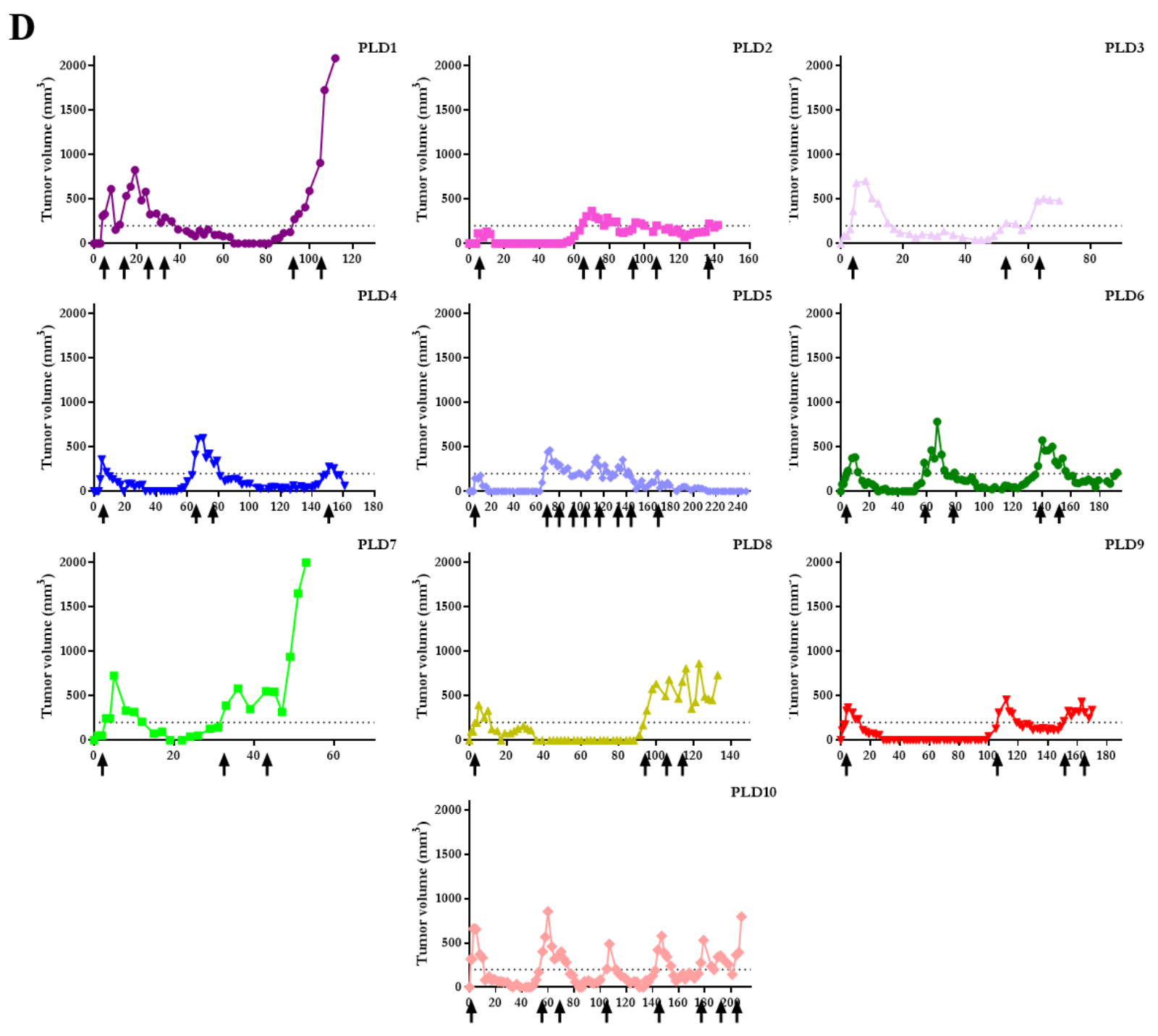

Fig. 2D. Growth kinetics of PLD treated individual tumors (PLD1-10). Arrows indicate treatment.

Resistance to doxorubicin can be overcome by PLD in the $\mathrm{Brcal}^{-/-} ; \mathrm{p5}^{-/-}$tumor model of hereditary mammary cancer

Although PLD proved ineffective against doxorubicin-resistant cell lines in vitro (Table 1) and in vivo (Figure 1), we also wanted to evaluate the potential of PLD against doxorubicin resistant mammary cancer using the model described above. Doxorubicin-resistant tumors (Fig. 
2C) were re-transplanted into the mammary fat pad of wild-type mice. After the tumors became palpable, mice were treated with the MTD of either DOX or PLD. As expected, doxorubicin treatment was largely ineffective (median overall survival was 27 days, as opposed to the median survival of 49.5 days observed when DOX was used in drug-sensitive tumors, Fig. 2B). Surprisingly, all the DOX resistant tumors responded to PLD treatment (Fig. 3B). Although the relapse-free period was significantly shorter (RFS of 56 vs 15 days, in first- and second-line PLD treatment groups, Fig. 2A and Fig. 3B, respectively), PLD treatment was able to significantly prolong the overall survival of mice bearing DOX-resistant tumors (OS of 151 vs 142 days, in the first- (Fig. 2B) and second-line (Fig. 3C) PLD treatment groups, respectively). Complete remission was achieved with one mouse (PLD16), which has been tumor-free for over 200 days. Only one of the 8 re-transplanted tumors became refractory to PLD treatment; all the others were efficiently contained until the experiment had to be stopped due to the cumulating toxicity associated with PLD treatment (Fig. 3A and Supplementary Fig. S2). 
A

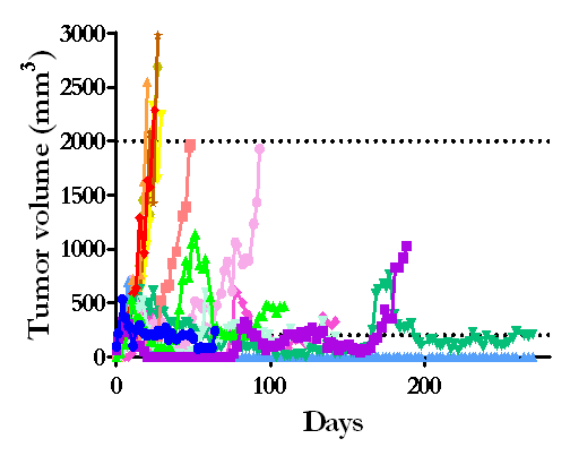

B

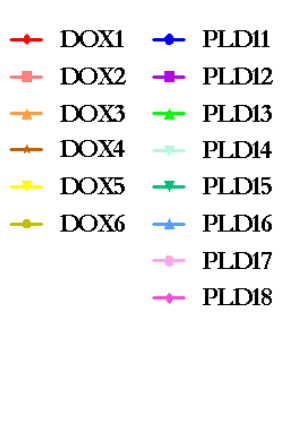

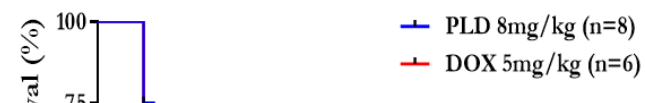

C

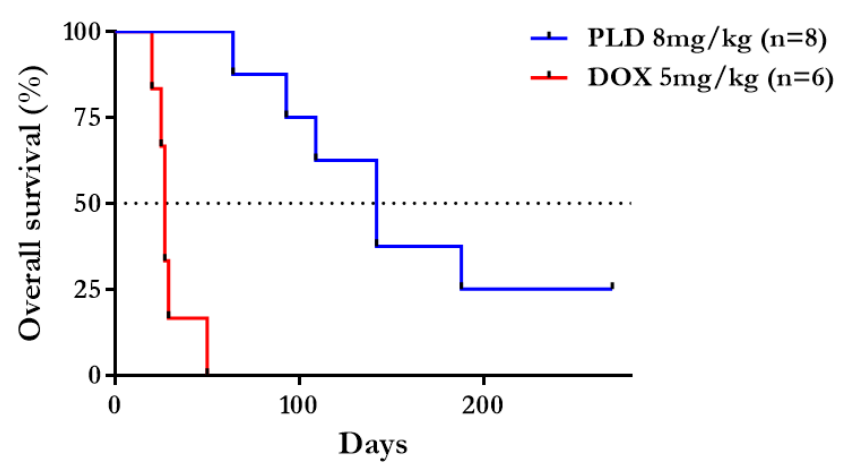

Fig. 3. PLD treatment of DOX-resistant tumors is remarkably effective A. Growth kinetics, B. Relapse-free survival and C. Overall survival of DOX-resistant tumors treated with DOX (5 $\mathrm{mg} / \mathrm{kg}$ iv.) or PLD (8 mg/kg iv.).

\section{PLD-resistant tumors show 20-400 fold higher expression of Abcb1a and Abcb1b}

Pgp expression conferred resistance to PLD in cytotoxity experiments and in the P388 MDR ascites tumor model. Also, as described by Rottenberg and colleagues, in the case of DOX, treatment failure was due to a moderately increased expression of Abcbla and b [19]. Strikingly, PLD-resistant tumors (PLD1 and 7) showed extremely high Abcb1a and b mRNA levels (200-400 fold increase as compared to the saline-treated group). Similarly, tumors showing signs of resistance towards the end of the experiment (PLD 3, 8, 10) exhibited very high Abcb1a and 
Abcb1b levels. Tumor tissue could not be extracted from responders (PLD 2, 4, 5, 9), except for PLD 6, which however did not overexpress any of the Abcb1 genes (Fig. 4).

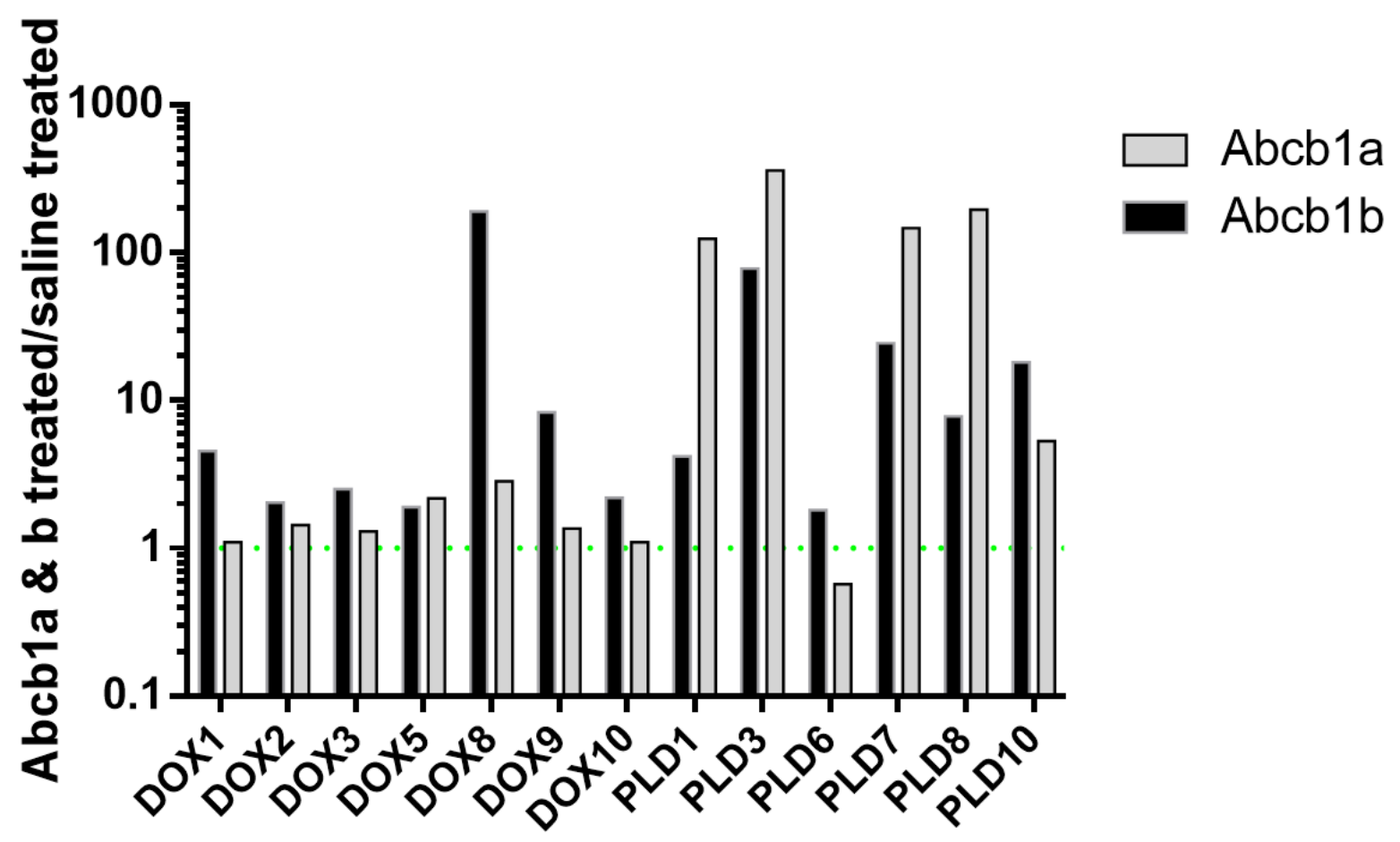

Fig. 4. Normalized Abcb1a and $A b c b 1 b$ mRNA expression levels in tumors treated with saline, DOX or PLD.

Superior activity of PLD over DOX can be explained by increased tumoral doxorubicin levels

Liposomal formulation of doxorubicin allowed a $60 \%$ increase of the MTD $(8 \mathrm{mg} / \mathrm{kg}$ vs 5 $\mathrm{mg} / \mathrm{kg}$ for PLD and DOX, respectively), which resulted in a 35-fold increase in the maximum peak doxorubicin concentration $(31600 \pm 6023 \mathrm{ng} / \mu \mathrm{l}$ vs $885.67 \pm 240$, measured $5 \mathrm{~min}$ after administration). Following intravenous injection of DOX, doxorubicin plasma levels decayed rapidly, whereas 7 days after treatment with a single dose of PLD, doxorubicin concentrations 
were still comparable to maximum levels observed in DOX-treated mice (Fig. 5A). Consequently, the AUC value was $\sim 2600$-fold higher for PLD as compared to DOX $\left(4.47 \times 10^{7}\right.$ vs $1.7 \times 10^{4}$ $\mathrm{ng} \times \mathrm{h} / \mathrm{ml}$ ). As expected based on the EPR effect, elevated plasma doxorubicin levels resulted in a significant increase of the tumoral drug load in the PLD-treated mice (Fig. 5B). Despite sustained high doxorubicin plasma concentrations, treatment with PLD was not limited by signs of pain, serious side effects or weight loss (see Supplementary Figure S4 for the histological analysis of vital organs). Long-term (>120 days) treatment with PLD however resulted in ulcerations reminiscent of the palmar-plantar erythrodysesthesia ("hand-foot syndrome") observed in patients [48].

A

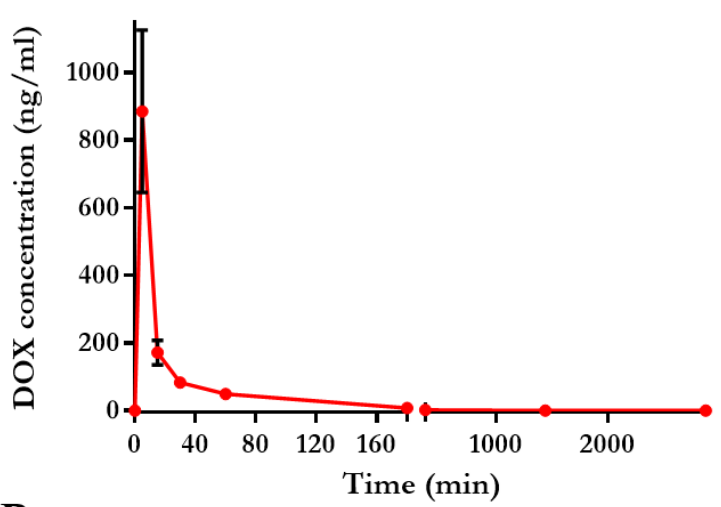

B

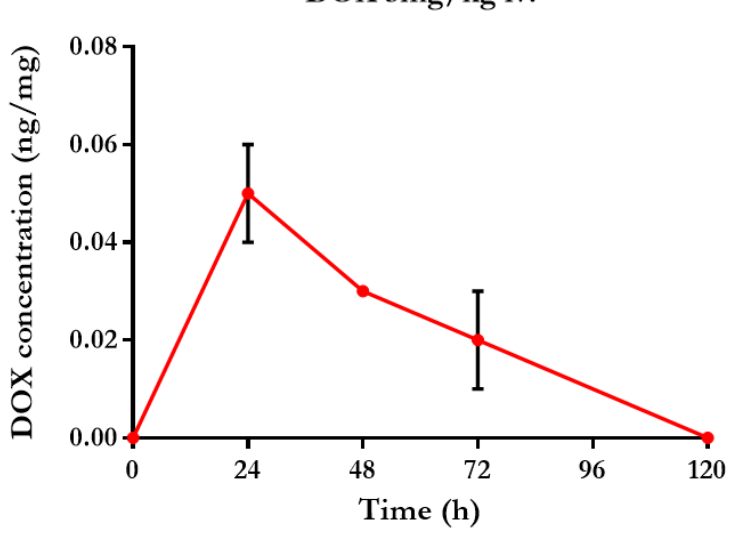

PLD $8 \mathrm{mg} / \mathrm{kg}$ iv.

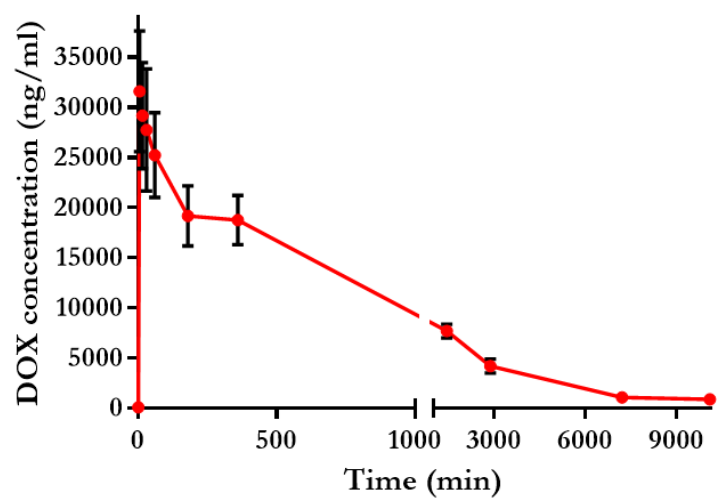

PLD 8mg/kg iv.

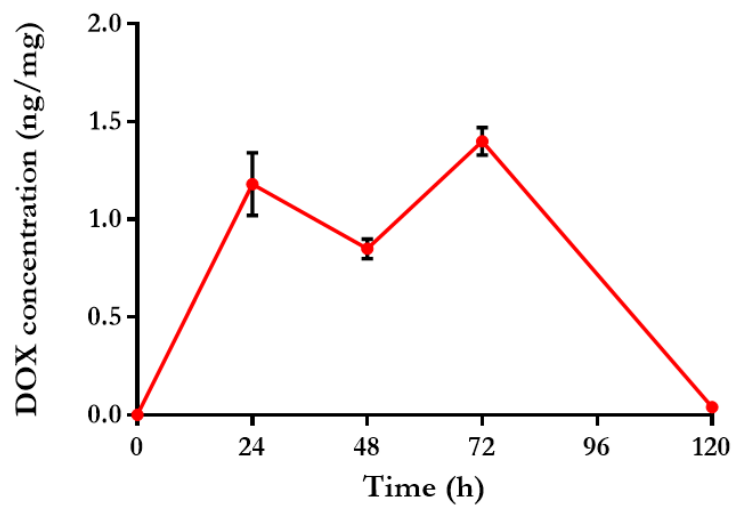


Fig. 5. Serum (A) and tumoral (B) doxorubicin concentrations in mice receiving DOX or PLD treatment. Mice were injected (time 0) with either doxorubicin at a dose of $5 \mathrm{mg} / \mathrm{kg}$ (left panels) or PLD at a dose of $8 \mathrm{mg} / \mathrm{kg}$ (right panels). Doxorubicin levels were determined at the indicated time points by mass spectroscopy. Points represent means of triplicate aliquots from 3 mice per time point; error bars represent \pm SD.

\section{BRCA1 knock-out cells show increased sensitivity to DOX and PLD}

The surprising efficacy of PLD in treatment-naïve and DOX-resistant Brca1-negative mammary tumors prompted us to investigate the relevance of defective homology-directed DNA repair. We compared the sensitivity of wild-type and a BRCA1-null DT40 cells against a panel of cytotoxic compounds used in the treatment of breast cancer. BRCA1 is not essential for survival of DT40 cells, which is likely due to p53 deficiency [49]. As expected, BRCAl-KO DT40 cells were hypersensitive to Olaparib and SN-38, but not to 5-fluorouracil (5-FU) or Paclitaxel. Surprisingly, BRCA1-deficient cells were also more sensitive to Topoisomerase II inhibitors. In particular, lack of BRCA1 resulted in a 3.3- and 2.8-fold higher sensitivity to DOX and PLD, respectively (Table 2).

\begin{tabular}{|c|c|c|c|c|}
\hline Mechanism of action & Compound & WT & BRCA1-/- & Selectivity \\
\hline \hline PARP-inhibitor & Olaparib & 3080 & 30 & $104.1^{* *}$ \\
\hline \hline topoisomerase II inhibitor & PLD & 229.4 & 82.9 & $2.8^{* *}$ \\
\cline { 2 - 5 } & Doxorubicin & 8.45 & 2.57 & $3.3^{* *}$ \\
\cline { 2 - 5 } & Daunorubicin & 4.68 & 2.51 & $1.9^{*}$ \\
\cline { 2 - 5 } & Etoposide & 51.0 & 29.3 & $1.7^{*}$ \\
\hline \hline topoisomerase I inhibitor & SN-38 & 4.60 & 0.49 & $9.4^{* *}$ \\
\hline \hline antimetabolite & $5-F U$ & 2.86 & 2.98 & 0.96 \\
\hline \hline microtubule-stabilizing agent & Paclitaxel & 384.5 & 448.2 & 0.86 \\
\hline
\end{tabular}


Table 2. Cytotoxicity $\left(\mathrm{IC}_{50}\right)$ of chemotherapeutics $(\mathrm{nM})$ used in the clinical treatment of breast cancer. Selectivity $>1$ indicates that the compound kills BRCA1-KO DT40 cells more effectively than parental DT40 cells. ${ }^{*} \mathrm{p}<0.05 ;{ }^{* *} \mathrm{p}<0.01$

\section{Discussion}

Effective treatment of cancer requires the use of toxic chemotherapy. In most cases, multiple drugs are used, as resistance to single agents occurs almost universally. One of the best studied mechanisms of multidrug resistance relies on the ability of P-glycoprotein to prevent drugs from reaching a toxic concentration inside cancer cells. Unfortunately, clinical efforts to inhibit efflux-mediated resistance have failed, due to unwanted side effects associated with the toxicity of the concomitantly administered chemotherapy [20]. A simple alternative to transporter inhibition would be to increase intracellular drug accumulation by elevating the dose of chemotherapy. However, while this approach may prove viable in vitro, even a slight increase in chemotherapy dosages can result in lethal side effects in patients. PLD was developed with the aim to overcome the dose-limiting cardiotoxicity and myelosuppression of doxorubicin [29]. Currently, PLD is approved for AIDS-related Kaposi's sarcoma, ovarian cancer (after failure of platinum-based therapy), and multiple myeloma (in combination with bortezomib in patients who have not previously received bortezomib and have received at least one prior therapy). In addition, several reports showed benefit in advanced, metastatic and recurrent breast cancers [50,51] even with prolonged dose intervals [52]. Interestingly, only a small number of studies were performed using PLD as a neoadjuvant treatment in locally advanced breast cancer patients [53]. To our knowledge there are no studies focusing on PLD-resistance in any kind of cancer. 
Since Pgp extrudes its substrates from the membrane bilayer (hydrophobic vacuum cleaner model [54]), liposomal formulations may bypass the transporter as they shuttle their cargo into the cells. Several studies suggested that nanomedicines can overcome MDR to some extent [55] [56] [57,58] [59], but a systematic analysis found that the overall benefit may be quite small [60]. In our hands, the in vitro toxicity of PLD was significantly reduced in sensitive cells, and Pgpexpressing cells were completely resistant (Table 1). However, in the case of PLD (but not DOX), we observed a gradual increase in the sensitivity and drug uptake of drug-sensitive cells. In contrast, MDR cells were resistant to both PLD and DOX even at later time points, and did not show any drug uptake unless Pgp was inhibited by Tariquidar (Supplementary Figures S3 and S5). These results are consistent with the slow extracellular release of free doxorubicin from PLD [61]. Since extracellularly released doxorubicin cannot cross the plasma membrane due to preemptive efflux by Pgp, MDR cells remain dim and resistant even at later time points.

PLD was also inefficient against drug resistant P388/ADR cells in an ascites tumor model despite the dose-dependent response of the Abcb1-negative tumors. Extrapolation of these results suggested that Doxil treatment would not be effective in treatment-refractory patients. However, failure of the clinical trials conducted with transporter inhibitors has shown the complexity of translating knowledge gained from in vitro models. The evolution of cancer drug resistance is a multi-step process, which is best modeled with clinically relevant mouse models of cancer [14]. To evaluate the clinical potential of PLD in treatment-naïve and therapy-resistant triple-negative breast cancer, we used a GEMM in which mammary tumors arise due to the tissue specific disruption of Brcal and $p 53$ [13]. An advantage of this model is that mammary tumors obtained

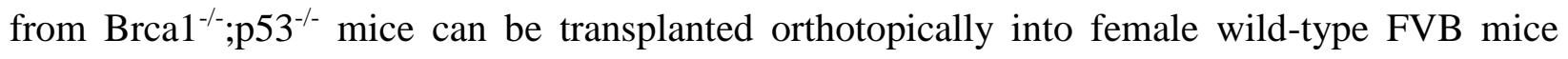
without the loss of histomorphological features, molecular characteristics and the drug sensitivity 
profile [17]. Although the incidence of BRCA1-deficient hereditary breast cancer is relatively low, the high prevalence of BRCA1 dysfunction identified in sporadic breast cancer [62] [63] could also be exploited. Reduced BRCA1 function as a result of gene silencing by hypermethylation was observed in sporadic breast and ovarian cancer [64,65], and BRCA1/2-deficiency is also present in non-gynecological malignancies [66].

In line with Phase 1 studies, we found that the circulation time, maximum peak concentration and AUC of doxorubicin were significantly higher in PLD treated groups as compared to DOX treatment $[30,53,67]$. PLD was far more efficient than DOX as reflected by a significant increase of both relapse-free and overall survival of Brca1-negative mammary tumor bearing mice (the relapse-free survival in the PLD treatment group (56 days) was longer than the overall survival of the DOX treated group (49.5 days)). Improved survival was clearly due to the delayed onset of drug resistance, suggesting that the increased cytotoxic payload could overwhelm the transporters expressed at relatively low levels. This result also highlights the shortcomings of typically used resistance models, which are based on the comparative study of sensitive and resistant cell lines in in vitro and xenograft experiments [60]. PLD was ineffective in the doxorubicin-resistant MES-SA/Dx5 [68] or P388/ADR cells and the retrovirally transduced A431/B1 cells because Pgp expression in these routinely used MDR cell lines is exceedingly high, whereas resistance of Brca1-negative mammary tumors to DOX was caused by a moderate overexpression of Abcb1/Pgp. The functional relevance of moderate transporter levels in conferring resistance to DOX or Olaparib has been previously established by demonstrating restoration of drug sensitivity with the addition of the Pgp antagonist tariquidar $[17,19]$. Strikingly, Abcb1/Pgp expression levels needed to confer resistance to PLD were 20 to 400 fold higher than those that conferred doxorubicin resistance, offering an explanation for the delayed and less 
frequent emergence of PLD resistance. The possible involvement of Pgp in limiting human breast cancer therapy is still controversial. While the level of Pgp needed to confer clinical resistance in human tumors has never been established due to the insensitivity of the methods, our results suggest that PLD-refractory patients express high Pgp levels that may be readily detected even in a routine clinical diagnostic setting.

Consistent with the higher Pgp levels needed to confer resistance, PLD administration was able to overcome doxorubicin insensitivity of the mouse mammary tumors. This may explain the result of the meta-analysis of four prospective trials, which proved that anthracycline re-challenge using PLD is effective in patients with metastatic breast cancer regardless of resistance, cumulative dose or time since prior conventional anthracycline therapy [69]. Likewise, a multicenter phase II study conducted on $79 \mathrm{MBC}$ patients previously treated with anthracyclines found that PLD was as effective as other commonly used salvage regimens (eg. capecitabine) [70]. PLD was also found to be efficient in BRCA-related ovarian cancer (OC) even after resistance to platinum based treatments have emerged [71]. Strikingly, comparison of PLD and olaparib in heavily pretreated BRCA-heterozygous OC patients demonstrated similar efficacy, suggesting that PLD may also be advantageous in BRCAl-negative cancers [72]. Although olaparib has potent antitumor activity in BRCA-negative cancers, not all patients with cancer who carry BRCA1 or BRCA2 mutations respond to PARPi therapy, and the analysis of BRCA1-mutated mouse mammary tumors suggested that olaparib resistance is also due to the moderate overexpression of Pgp [73]. In light of our results, the clinical benefit of PLD re-challenge may be explained by the ability of PLD to overcome Pgp-mediated resistance that limits the efficiency of anthracycline-, taxane-, or olaparibbased regimens. 
While the effectiveness of PARP inhibitors for BRCA-deficient cells makes these the preferred agents for tumors harboring such cells, the choice of "cytotoxic" agent to use in the therapy of BRCA-deficient cells is less clear. Persuasive basic science suggests a topoisomerase I inhibitor should be the preferred agent $[74,75]$ but clinically cisplatin has often been administered in drug combinations with evidence of benefit [76-81]. As expected, our in vitro studies demonstrate that BRCA-deficient cells are markedly sensitive to olaparib. Whereas drug uptake was not effected by BRCA1 (Supplementary Figure S3), we also found collateral sensitivity to doxorubicin and PLD, suggestive of some level of synthetic lethality. Furthermore, our in vivo experiments demonstrated a nearly 6-fold prolongation of disease free-recurrence and a 3-fold increase of overall survival with PLD compared to doxorubicin. By stabilizing the topoisomerase II complex after it has broken the DNA chain for replication, doxorubicin prevents the resealing of the DNA double helix, stops replication and leads primarily to DNA double strand breaks. This may explain the sensitivity of BRCA1 mutant cells to DOX and PLD, as BRCAl plays an important role in DNA double strand break repair [82]. Whether this might render BRCA-deficient tumors more sensitive to doxorubicin will need to be more clearly established, but in our view it may be worthy of consideration given liposomal doxorubicin is used often in the therapy of ovarian cancer and less often in breast cancer.

This possible selectivity to BRCA1-deficient tumors, the high serum concentrations, the prolonged circulation time and the indirect targeting of tumor tissue by damaged blood vessel integrity could explain PLD's significant success over conventional DOX treatment. In addition, we show that the favorable pharmacokinetics achieved with PLD- a remarkable 2,600-fold higher AUC and a concomitant increase of the tumoral drug load- can effectively overcome Pgpmediated DOX resistance. In response to the critical shortage of PLD, the US Food and Drug 
Administration (FDA) allowed temporary importation of non-FDA-approved second-generation liposomal doxorubicin. With the expiry of the PLD patent, it is likely that several generics will be approved, which may also lead to the expansion of the current indications [29]. Considering the clinical failure of the many Pgp inhibitors that were previously developed and that were often encumbered by the need to reduce the doses of the concomitantly administered chemotherapy, novel formulations - liposomal, or nanoparticle - might offer a better alternative at reversing transporter mediated resistance. This is especially relevant given the heightened interest in such formulations as evidenced by four US FDA and EMA approvals in the recent past - including nanoparticle-albumin bound paclitaxel, doxorubicin hydrochloride liposome injection, irinotecan liposome injection and vincristine sulfate liposome injection. Approval is also expected for the first liposomal fixed drug combination of cytarabine and daunorubicin that will be used in AML [83].

\section{Conclusion}

Pegylated liposomal formulation of doxorubicin has a significant impact on the evolution of drug resistance in cancer. While treatment with doxorubicin becomes rapidly inefficient, pegylated liposomal doxorubicin dramatically increases relapse-free and overall survival due to the delayed onset of multidrug resistance. Our results also show that P-glycoprotein is able to confer resistance against liposomal drug formulations, albeit at significantly higher levels that may not be readily achieved in patients. Consistent with the higher Pgp levels needed to confer resistance, PLD administration was able to overcome doxorubicin insensitivity of the mouse mammary tumors, suggesting that encapsulated doxorubicin can successfully evade moderate Pgp levels associated with acquired resistance to anthracyclines or olaparib. Our data suggest that PLD therapy could be 
a promising strategy in breast cancer, not only in the metastatic stage, but also as a neoadjuvant treatment.

Acknowledgement: We thank Irén Bodrogi-Mayer, Anita Hídvégi and Annamária Tóth, Ibolya Kurkó for the excellent technical assistance; and Dr. Tito Fojo for useful comments. Funding: G.Sz. was supported by a Momentum Grant from the Hungarian Academy of Sciences and the ERC Starting grant 260572. Funding from the Austrian Science Fund SFB35 (GSzakács) is also acknowledged. Author contributions: Designed the experiments: A.F. and G.Sz. In vitro experiments: A.F., K.Sz., Sz.T., V.N., L.H., E.K.; in vivo studies: A.F., E.K., M.Cs., J.T.; tumor sample characterization: A.F., K.Sz., L.H., Cs.M., P.V.; mass spectrometry: I.T., P.Sz.; wrote the manuscript: A.F. and G.Sz. Competing interests: The authors declare no competing interests.

\section{Figure legends}

Fig. 1. DOX and PLD are ineffective in an ascites model of resistant leukemia. Drug-naive P388 or drug resistant P388/ADR tumor bearing mice were treated with saline (green and pink), 3 $\mathrm{mg} / \mathrm{kg}$ of DOX (red and blue) or PLD (orange and black) or $5 \mathrm{mg} / \mathrm{kg}$ of PLD (dashed dotted orange and black). The dotted vertical line indicates the time of treatment (T) at Day 2.

Fig. 2. PLD is superior to DOX in a clinically relevant mouse model of breast cancer. A. Relapse-free and B. Overall survival of DOX (5 mg/kg iv) and PLD (8 mg/kg iv) treated groups. C. Growth kinetics of saline (upper left panel), DOX (DOX1-10) and D. PLD (PLD1-10) treated individual tumors. Arrows indicate treatment. 
Fig. 3. PLD treatment of DOX-resistant tumors is remarkably effective A. Growth kinetics, B. Relapse-free survival and C. Overall survival of DOX-resistant tumors treated with DOX (5 $\mathrm{mg} / \mathrm{kg}$ iv.) or PLD (8 mg/kg iv.).

Fig. 4. Normalized $A b c b 1 a$ and $A b c b 1 b$ mRNA expression levels in tumors treated with saline, DOX or PLD.

Fig. 5. Serum (A) and tumoral (B) doxorubicin concentrations in mice receiving DOX or PLD treatment. Mice were injected (time 0) with either doxorubicin at a dose of $5 \mathrm{mg} / \mathrm{kg}$ (left panels) or PLD at a dose of $8 \mathrm{mg} / \mathrm{kg}$ (right panels). Doxorubicin levels were determined at the indicated time points by mass spectroscopy. Points represent means of triplicate aliquots from 3 mice per time point; error bars represent \pm SD.

\section{List of Supplementary Materials:}

Supplementary Table S1. In vitro toxicity $\left(\mathrm{IC}_{50}\right)$ of DOX and PLD in parental and ABCG2expressing A431 cells.

Supplementary Figure S1. Morphological comparison of three randomly selected, hematoxilin \& eosin stained tumor samples per each treatment group shown in Figure 2.

Supplementary Figure S2. Growth curves of DOX-resistant tumors treated with DOX (DOX 1-6) or PLD (PLD 11-18) shown in Fig. 3.

Supplementary Figure S3. In vitro studies measuring cellular fluorescence upon treatment with DOX or PLD.

Supplementary Figure S4. Histopathological analysis of vital organs: effect of DOX and PLD treatment 
Supplementary Figure S5. Cytotoxicity assays comparing the time-dependent toxicity of DOX and

PLD. 


\section{References}

[1] R. Siegel, D. Naishadham, A. Jemal, Cancer statistics, 2012, CA. Cancer J. Clin. 62 (2012) 10-29. doi:10.3322/caac.20138.

[2] T.R. Wilson, P.G. Johnston, D.B. Longley, Anti-apoptotic mechanisms of drug resistance in cancer, Curr. Cancer Drug Targets. 9 (2009) 307-319.

[3] P.-E. Colombo, F. Milanezi, B. Weigelt, J.S. Reis-Filho, Microarrays in the 2010s: the contribution of microarray-based gene expression profiling to breast cancer classification, prognostication and prediction, Breast Cancer Res. BCR. 13 (2011) 212. doi:10.1186/bcr2890.

[4] J. O'Shaughnessy, Extending survival with chemotherapy in metastatic breast cancer, The Oncologist. 10 Suppl 3 (2005) 20-29. doi:10.1634/theoncologist.10-90003-20.

[5] J. Cortes, J. Baselga, Targeting the microtubules in breast cancer beyond taxanes: the epothilones, The Oncologist. 12 (2007) 271-280. doi:10.1634/theoncologist.12-3-271.

[6] M. Castells, B. Thibault, J.-P. Delord, B. Couderc, Implication of tumor microenvironment in chemoresistance: tumor-associated stromal cells protect tumor cells from cell death, Int. J. Mol. Sci. 13 (2012) 9545-9571. doi:10.3390/ijms13089545.

[7] M.M. Gottesman, Mechanisms of cancer drug resistance, Annu. Rev. Med. 53 (2002) 615627. doi:10.1146/annurev.med.53.082901.103929.

[8] M.M. Gottesman, T. Fojo, S.E. Bates, Multidrug resistance in cancer: role of ATPdependent transporters, Nat Rev Cancer. 2 (2002) 48-58. 
[9] R. Pirker, J. Wallner, M. Götzl, A. Gsur, K. Geissler, L. Havelec, W. Knapp, O. Haas, W. Linkesch, K. Lechner, MDR1 RNA expression is an independent prognostic factor in acute myeloid leukemia, Blood. 80 (1992) 557-559.

[10] C. Doxani, M. Voulgarelis, E. Zintzaras, MDR1 mRNA expression and MDR1 gene variants as predictors of response to chemotherapy in patients with acute myeloid leukaemia: a meta-analysis, Biomark. Biochem. Indic. Expo. Response Susceptibility Chem. 18 (2013) 425-435. doi:10.3109/1354750X.2013.808263.

[11] L. Campos, D. Guyotat, E. Archimbaud, P. Calmard-Oriol, T. Tsuruo, J. Troncy, D. Treille, D. Fiere, Clinical significance of multidrug resistance P-glycoprotein expression on acute nonlymphoblastic leukemia cells at diagnosis, Blood. 79 (1992) 473-476.

[12] E. Karaszi, K. Jakab, L. Homolya, G. Szakacs, Z. Hollo, B. Telek, A. Kiss, L. Rejtô, S. Nahajevszky, B. Sarkadi, Calcein assay for multidrug resistance reliably predicts therapy response and survival rate in acute myeloid leukaemia, Br. J. Haematol. 112 (2001) 308314.

[13] X. Liu, H. Holstege, H. van der Gulden, M. Treur-Mulder, J. Zevenhoven, A. Velds, R.M. Kerkhoven, M.H. van Vliet, L.F. Wessels, J.L. Peterse, Somatic loss of BRCA1 and p53 in mice induces mammary tumors with features of human BRCA1-mutated basal-like breast cancer, Proc. Natl. Acad. Sci. 104 (2007) 12111-12116.

[14] S. Rottenberg, P. Borst, Drug resistance in the mouse cancer clinic, Drug Resist. Updat. 15 (2012) 81-89. doi:10.1016/j.drup.2012.01.001.

[15] S. Rottenberg, J. Jonkers, Modeling therapy resistance in genetically engineered mouse cancer models, Drug Resist. Updat. 11 (2008) 51-60. doi:10.1016/j.drup.2007.11.002. 
[16] P.C. Fong, D.S. Boss, T.A. Yap, A. Tutt, P. Wu, M. Mergui-Roelvink, P. Mortimer, H. Swaisland, A. Lau, M.J. O’Connor, A. Ashworth, J. Carmichael, S.B. Kaye, J.H.M. Schellens, J.S. de Bono, Inhibition of poly(ADP-ribose) polymerase in tumors from BRCA mutation carriers, N. Engl. J. Med. 361 (2009) 123-134. doi:10.1056/NEJMoa0900212.

[17] S. Rottenberg, A.O.H. Nygren, M. Pajic, F.W.B. van Leeuwen, I. van der Heijden, K. van de Wetering, X. Liu, K.E. de Visser, K.G. Gilhuijs, O. van Tellingen, J.P. Schouten, J. Jonkers, P. Borst, Selective induction of chemotherapy resistance of mammary tumors in a conditional mouse model for hereditary breast cancer, Proc. Natl. Acad. Sci. U. S. A. 104 (2007) 12117-12122. doi:10.1073/pnas.0702955104.

[18] S.A.L. Zander, A. Kersbergen, E. van der Burg, N. de Water, O. van Tellingen, S. Gunnarsdottir, J.E. Jaspers, M. Pajic, A.O.H. Nygren, J. Jonkers, P. Borst, S. Rottenberg, Sensitivity and Acquired Resistance of BRCA1;p53-Deficient Mouse Mammary Tumors to the Topoisomerase I Inhibitor Topotecan, Cancer Res. 70 (2010) 1700-1710. doi:10.1158/0008-5472.CAN-09-3367.

[19] M. Pajic, J.K. Iyer, A. Kersbergen, E. van der Burg, A.O.H. Nygren, J. Jonkers, P. Borst, S. Rottenberg, Moderate increase in Mdr1a/1b expression causes in vivo resistance to doxorubicin in a mouse model for hereditary breast cancer, Cancer Res. 69 (2009) 63966404. doi:10.1158/0008-5472.CAN-09-0041.

[20] G. Szakacs, J.K. Paterson, J.A. Ludwig, C. Booth-Genthe, M.M. Gottesman, Targeting multidrug resistance in cancer, Nat Rev Drug Discov. 5 (2006) 219-34.

[21] G. Szakács, J.-P. Annereau, S. Lababidi, U. Shankavaram, A. Arciello, K.J. Bussey, W. Reinhold, Y. Guo, G.D. Kruh, M. Reimers, J.N. Weinstein, M.M. Gottesman, Predicting 
drug sensitivity and resistance: profiling $\mathrm{ABC}$ transporter genes in cancer cells, Cancer Cell. 6 (2004) 129-137. doi:10.1016/j.ccr.2004.06.026.

[22] D. Türk, M.D. Hall, B.F. Chu, J.A. Ludwig, H.M. Fales, M.M. Gottesman, G. Szakács, Identification of Compounds Selectively Killing Multidrug-Resistant Cancer Cells, Cancer Res. 69 (2009) 8293-8301. doi:10.1158/0008-5472.CAN-09-2422.

[23] A. Füredi, S. Tóth, K. Szebényi, V.F.S. Pape, D. Türk, N. Kucsma, L. Cervenák, J. Tóvári, G. Szakács, Identification and validation of compounds selectively killing resistant cancer: delineating cell line specific effects from P-glycoprotein-induced toxicity, Mol. Cancer Ther. (2016) molcanther.0333.2016. doi:10.1158/1535-7163.MCT-16-0333-T.

[24] G. Szakács, M.D. Hall, M.M. Gottesman, A. Boumendjel, R. Kachadourian, B.J. Day, H. Baubichon-Cortay, A. Di Pietro, Targeting the Achilles Heel of Multidrug-Resistant Cancer by Exploiting the Fitness Cost of Resistance, Chem. Rev. 114 (2014) 5753-5774. doi: $10.1021 / \mathrm{cr} 4006236$.

[25] L. Fang, G. Zhang, C. Li, X. Zheng, L. Zhu, J.J. Xiao, G. Szakacs, J. Nadas, K.K. Chan, P.G. Wang, D. Sun, Discovery of a daunorubicin analogue that exhibits potent antitumor activity and overcomes P-gp-mediated drug resistance, J. Med. Chem. 49 (2006) 932-941. doi:10.1021/jm050800q.

[26] R.B. Weiss, The anthracyclines: will we ever find a better doxorubicin?, Semin. Oncol. 19 (1992) 670-686.

[27] Handbook of Cancer Chemotherapy 8th edition (9781608317820) - Textbooks.com, (n.d.). http://www.textbooks.com/Handbook-of-Cancer-Chemotherapy-8thEdition/9781608317820/Roland-T-Skeel-and-Samir-Khleif.php (accessed January 2, 2017). 
[28] G. Minotti, P. Menna, E. Salvatorelli, G. Cairo, L. Gianni, Anthracyclines: molecular advances and pharmacologic developments in antitumor activity and cardiotoxicity, Pharmacol. Rev. 56 (2004) 185-229. doi:10.1124/pr.56.2.6.

[29] Y. Barenholz, Doxil®--the first FDA-approved nano-drug: lessons learned, J. Control. Release Off. J. Control. Release Soc. 160 (2012) 117-134. doi:10.1016/j.jconrel.2012.03.020.

[30] A. Gabizon, R. Catane, B. Uziely, B. Kaufman, T. Safra, R. Cohen, F. Martin, A. Huang, Y. Barenholz, Prolonged circulation time and enhanced accumulation in malignant exudates of doxorubicin encapsulated in polyethylene-glycol coated liposomes, Cancer Res. 54 (1994) 987-992.

[31] H. Hashizume, P. Baluk, S. Morikawa, J.W. McLean, G. Thurston, S. Roberge, R.K. Jain, D.M. McDonald, Openings between defective endothelial cells explain tumor vessel leakiness, Am. J. Pathol. 156 (2000) 1363-1380. doi:10.1016/S0002-9440(10)65006-7.

[32] R. Bassermann, Changes of vascular pattern of tumors and surrounding tissue during different phases of metastatic growth, Recent Results Cancer Res. Fortschritte Krebsforsch. Progres Dans Rech. Sur Cancer. 100 (1986) 256-267.

[33] S.K. Huang, K.D. Lee, K. Hong, D.S. Friend, D. Papahadjopoulos, Microscopic localization of sterically stabilized liposomes in colon carcinoma-bearing mice, Cancer Res. 52 (1992) 5135-5143.

[34] J. Vaage, E. Mayhew, D. Lasic, F. Martin, Therapy of primary and metastatic mouse mammary carcinomas with doxorubicin encapsulated in long circulating liposomes, Int. J. Cancer. 51 (1992) 942-948. 
[35] J. Vaage, D. Donovan, E. Mayhew, R. Abra, A. Huang, Therapy of human ovarian carcinoma xenografts using doxorubicin encapsulated in sterically stabilized liposomes, Cancer. 72 (1993) 3671-3675.

[36] G.T. Colbern, A.J. Hiller, R.S. Musterer, E. Pegg, I.C. Henderson, P.K. Working, Significant Increase in Antitumor Potency of Doxorubicin Hc1 by its Encapsulation in Pegylated Liposomes, J. Liposome Res. 9 (1999) 523-538. doi:10.3109/08982109909035551.

[37] P.K. Working, A.D. Dayan, Pharmacological-toxicological expert report. CAELYX. (Stealth liposomal doxorubicin HCl), Hum. Exp. Toxicol. 15 (1996) 751-785.

[38] A. Cabanes, D. Tzemach, D. Goren, A.T. Horowitz, A. Gabizon, Comparative study of the antitumor activity of free doxorubicin and polyethylene glycol-coated liposomal doxorubicin in a mouse lymphoma model, Clin. Cancer Res. Off. J. Am. Assoc. Cancer Res. 4 (1998) 499-505.

[39] R. Mazurchuk, D. Glaves, D. Raghavan, Magnetic resonance imaging of response to chemotherapy in orthotopic xenografts of human bladder cancer, Clin. Cancer Res. Off. J. Am. Assoc. Cancer Res. 3 (1997) 1635-1641.

[40] J. Vaage, E. Barberá-Guillem, R. Abra, A. Huang, P. Working, Tissue distribution and therapeutic effect of intravenous free or encapsulated liposomal doxorubicin on human prostate carcinoma xenografts, Cancer. 73 (1994) 1478-1484.

[41] D.M. Vail, M.A. Amantea, G.T. Colbern, F.J. Martin, R.A. Hilger, P.K. Working, Pegylated liposomal doxorubicin: proof of principle using preclinical animal models and pharmacokinetic studies, Semin Oncol. 31 (2004) 16-35. 
[42] J.A. O'Shaughnessy, Pegylated liposomal doxorubicin in the treatment of breast cancer, Clin. Breast Cancer. 4 (2003) 318-328.

[43] E. Mechetner, A. Kyshtoobayeva, S. Zonis, H. Kim, R. Stroup, R. Garcia, R.J. Parker, J.P. Fruehauf, Levels of multidrug resistance (MDR1) P-glycoprotein expression by human breast cancer correlate with in vitro resistance to taxol and doxorubicin, Clin. Cancer Res. Off. J. Am. Assoc. Cancer Res. 4 (1998) 389-398.

[44] J.M. Buerstedde, C.A. Reynaud, E.H. Humphries, W. Olson, D.L. Ewert, J.C. Weill, Light chain gene conversion continues at high rate in an ALV-induced cell line, EMBO J. 9 (1990) 921-927.

[45] C.J. Vandenberg, F. Gergely, C.Y. Ong, P. Pace, D.L. Mallery, K. Hiom, K.J. Patel, BRCA1-independent ubiquitination of FANCD2, Mol. Cell. 12 (2003) 247-254.

[46] L.H. Saal, S.K. Gruvberger-Saal, C. Persson, K. Lövgren, M. Jumppanen, J. Staaf, G. Jönsson, M.M. Pires, M. Maurer, K. Holm, S. Koujak, S. Subramaniyam, J. VallonChristersson, H. Olsson, T. Su, L. Memeo, T. Ludwig, S.P. Ethier, M. Krogh, M. Szabolcs, V.V.V.S. Murty, J. Isola, H. Hibshoosh, R. Parsons, A. Borg, Recurrent gross mutations of the PTEN tumor suppressor gene in breast cancers with deficient DSB repair, Nat. Genet. 40 (2008) 102-107. doi:10.1038/ng.2007.39.

[47] G. Szakács, M.M. Gottesman, Comparing Solid Tumors with Cell Lines: Implications for Identifying Drug Resistance Genes in Cancer, Mol. Interv. 4 (2004) 323. doi:10.1124/mi.4.6.5.

[48] D. Lorusso, A. Di Stefano, V. Carone, A. Fagotti, S. Pisconti, G. Scambia, Pegylated liposomal doxorubicin-related palmar-plantar erythrodysesthesia ("hand-foot" syndrome), 
Ann. Oncol. Off. J. Eur. Soc. Med. Oncol. 18 (2007) 1159-1164.

doi:10.1093/annonc/mdl477.

[49] R.W. Martin, B.J. Orelli, M. Yamazoe, A.J. Minn, S. Takeda, D.K. Bishop, RAD51 Upregulation Bypasses BRCA1 Function and Is a Common Feature of BRCA1-Deficient Breast Tumors, Cancer Res. 67 (2007) 9658-9665. doi:10.1158/0008-5472.CAN-07-0290.

[50] J.A. Sparano, A.N. Makhson, V.F. Semiglazov, S.A. Tjulandin, O.I. Balashova, I.N. Bondarenko, N.V. Bogdanova, G.M. Manikhas, G.P. Oliynychenko, V.A. Chatikhine, S.H. Zhuang, L. Xiu, Z. Yuan, W.R. Rackoff, Pegylated liposomal doxorubicin plus docetaxel significantly improves time to progression without additive cardiotoxicity compared with docetaxel monotherapy in patients with advanced breast cancer previously treated with neoadjuvant-adjuvant anthracycline therapy: results from a randomized phase III study, J. Clin. Oncol. Off. J. Am. Soc. Clin. Oncol. 27 (2009) 4522-4529. doi:10.1200/JCO.2008.20.5013.

[51] A.T. Perez, G.H. Domenech, C. Frankel, C.L. Vogel, Pegylated liposomal doxorubicin (Doxil) for metastatic breast cancer: the Cancer Research Network, Inc., experience, Cancer Invest. 20 Suppl 2 (2002) 22-29.

[52] A. Hamilton, L. Biganzoli, R. Coleman, L. Mauriac, P. Hennebert, A. Awada, M. Nooij, L. Beex, M. Piccart, I. Van Hoorebeeck, P. Bruning, D. de Valeriola, EORTC 10968: a phase I clinical and pharmacokinetic study of polyethylene glycol liposomal doxorubicin (Caelyx, Doxil) at a 6-week interval in patients with metastatic breast cancer. European Organization for Research and Treatment of Cancer, Ann. Oncol. Off. J. Eur. Soc. Med. Oncol. 13 (2002) 910-918. 
[53] J. Lao, J. Madani, T. Puértolas, M. Alvarez, A. Hernández, R. Pazo-Cid, A. Artal, A. Antón Torres, Liposomal Doxorubicin in the treatment of breast cancer patients: a review, J. Drug Deliv. 2013 (2013) 456409. doi:10.1155/2013/456409.

[54] I. Pastan, M.M. Gottesman, Multidrug resistance, Annu Rev Med. 42 (1991) 277-86.

[55] A.L.B. Seynhaeve, B.M. Dicheva, S. Hoving, G.A. Koning, T.L.M. ten Hagen, Intact Doxil is taken up intracellularly and released doxorubicin sequesters in the lysosome: evaluated by in vitro/in vivo live cell imaging, J. Control. Release Off. J. Control. Release Soc. 172 (2013) 330-340. doi:10.1016/j.jconrel.2013.08.034.

[56] M.L. Krieger, A. Konold, M. Wiese, U. Jaehde, G. Bendas, Targeted doxorubicinliposomes as a tool to circumvent P-gp-mediated resistance in ovarian carcinoma cells, ResearchGate. 48 (2010) 442-4. doi:10.5414/CPP48442.

[57] E.V. Batrakova, S. Li, A.M. Brynskikh, A.K. Sharma, Y. Li, M. Boska, N. Gong, R.L. Mosley, V.Y. Alakhov, H.E. Gendelman, A.V. Kabanov, Effects of pluronic and doxorubicin on drug uptake, cellular metabolism, apoptosis and tumor inhibition in animal models of MDR cancers, J. Controlled Release. 143 (2010) 290-301. doi:10.1016/j.jconrel.2010.01.004.

[58] A.K. Iyer, A. Singh, S. Ganta, M.M. Amiji, Role of integrated cancer nanomedicine in overcoming drug resistance, Adv. Drug Deliv. Rev. 65 (2013) 1784-1802. doi:10.1016/j.addr.2013.07.012.

[59] M. Lelle, C. Freidel, S. Kaloyanova, I. Tabujew, A. Schramm, M. Musheev, C. Niehrs, K. Müllen, K. Peneva, Overcoming drug resistance by cell-penetrating peptide-mediated delivery of a doxorubicin dimer with high DNA-binding affinity, Eur. J. Med. Chem. 130 (2017) 336-345. doi:10.1016/j.ejmech.2017.02.056. 
[60] S. Kunjachan, A. B?au?, D. M?ckel, B. Theek, F. Kiessling, T. Etrych, K. Ulbrich, L. van Bloois, G. Storm, G. Bartosz, B. Rychlik, T. Lammers, Overcoming cellular multidrug resistance using classical nanomedicine formulations, Eur. J. Pharm. Sci. 45 (2012) 421428. doi:10.1016/j.ejps.2011.08.028.

[61] A.A. Gabizon, Y. Patil, N.M. La-Beck, New insights and evolving role of pegylated liposomal doxorubicin in cancer therapy, Drug Resist. Updat. 29 (2016) 90-106. doi:10.1016/j.drup.2016.10.003.

[62] M.E. Thompson, R.A. Jensen, P.S. Obermiller, D.L. Page, J.T. Holt, Decreased expression of BRCA1 accelerates growth and is often present during sporadic breast cancer progression, Nat. Genet. 9 (1995) 444-450. doi:10.1038/ng0495-444.

[63] N.C. Turner, J.S. Reis-Filho, A.M. Russell, R.J. Springall, K. Ryder, D. Steele, K. Savage, C.E. Gillett, F.C. Schmitt, A. Ashworth, A.N. Tutt, BRCA1 dysfunction in sporadic basallike breast cancer, Oncogene. 26 (2007) 2126-2132. doi:10.1038/sj.onc.1210014.

[64] N. Turner, A. Tutt, A. Ashworth, Hallmarks of "BRCAness" in sporadic cancers, Nat. Rev. Cancer. 4 (2004) 814-819. doi:10.1038/nrc1457.

[65] M. Esteller, J.M. Silva, G. Dominguez, F. Bonilla, X. Matias-Guiu, E. Lerma, E. Bussaglia, J. Prat, I.C. Harkes, E.A. Repasky, E. Gabrielson, M. Schutte, S.B. Baylin, J.G. Herman, Promoter hypermethylation and BRCA1 inactivation in sporadic breast and ovarian tumors, J. Natl. Cancer Inst. 92 (2000) 564-569.

[66] C.C. Pritchard, J. Mateo, M.F. Walsh, N. De Sarkar, W. Abida, H. Beltran, A. Garofalo, R. Gulati, S. Carreira, R. Eeles, O. Elemento, M.A. Rubin, D. Robinson, R. Lonigro, M. Hussain, A. Chinnaiyan, J. Vinson, J. Filipenko, L. Garraway, M.-E. Taplin, S. AlDubayan, G.C. Han, M. Beightol, C. Morrissey, B. Nghiem, H.H. Cheng, B. Montgomery, T. Walsh, 
S. Casadei, M. Berger, L. Zhang, A. Zehir, J. Vijai, H.I. Scher, C. Sawyers, N. Schultz, P.W. Kantoff, D. Solit, M. Robson, E.M. Van Allen, K. Offit, J. de Bono, P.S. Nelson, Inherited DNA-Repair Gene Mutations in Men with Metastatic Prostate Cancer, N. Engl. J. Med. 375 (2016) 443-453. doi:10.1056/NEJMoa1603144.

[67] M.E.R. O'Brien, N. Wigler, M. Inbar, R. Rosso, E. Grischke, A. Santoro, R. Catane, D.G. Kieback, P. Tomczak, S.P. Ackland, F. Orlandi, L. Mellars, L. Alland, C. Tendler, CAELYX Breast Cancer Study Group, Reduced cardiotoxicity and comparable efficacy in a phase III trial of pegylated liposomal doxorubicin $\mathrm{HCl}$ (CAELYX/Doxil) versus conventional doxorubicin for first-line treatment of metastatic breast cancer, Ann. Oncol. Off. J. Eur. Soc. Med. Oncol. 15 (2004) 440-449.

[68] W.G. Harker, F.R. MacKintosh, B.I. Sikic, Development and characterization of a human sarcoma cell line, MES-SA, sensitive to multiple drugs, Cancer Res. 43 (1983) 4943-4950.

[69] S.-E. Al-Batran, M. Güntner, C. Pauligk, M. Scholz, R. Chen, B. Beiss, S. Stopatschinskaja, W. Lerbs, N. Harbeck, E. Jäger, Anthracycline rechallenge using pegylated liposomal doxorubicin in patients with metastatic breast cancer: a pooled analysis using individual data from four prospective trials, Br. J. Cancer. 103 (2010) 1518-1523. doi:10.1038/sj.bjc.6605961.

[70] S.-E. Al-Batran, J. Bischoff, G. von Minckwitz, A. Atmaca, U. Kleeberg, I. Meuthen, G. Morack, W. Lerbs, D. Hecker, J. Sehouli, A. Knuth, E. Jager, The clinical benefit of pegylated liposomal doxorubicin in patients with metastatic breast cancer previously treated with conventional anthracyclines: a multicentre phase II trial, Br. J. Cancer. 94 (2006) 1615-1620. doi:10.1038/sj.bjc.6603158. 
[71] T. Safra, L. Borgato, M.O. Nicoletto, L. Rolnitzky, S. Pelles-Avraham, R. Geva, M.E. Donach, J. Curtin, A. Novetsky, T. Grenader, W.-C.V. Lai, A. Gabizon, L. Boyd, F. Muggia, BRCA mutation status and determinant of outcome in women with recurrent epithelial ovarian cancer treated with pegylated liposomal doxorubicin, Mol. Cancer Ther. 10 (2011) 2000-2007. doi:10.1158/1535-7163.MCT-11-0272.

[72] S.B. Kaye, J. Lubinski, U. Matulonis, J.E. Ang, C. Gourley, B.Y. Karlan, A. Amnon, K.M. Bell-McGuinn, L.-M. Chen, M. Friedlander, T. Safra, I. Vergote, M. Wickens, E.S. Lowe, J. Carmichael, B. Kaufman, Phase II, open-label, randomized, multicenter study comparing the efficacy and safety of olaparib, a poly (ADP-ribose) polymerase inhibitor, and pegylated liposomal doxorubicin in patients with BRCA1 or BRCA2 mutations and recurrent ovarian cancer, J. Clin. Oncol. Off. J. Am. Soc. Clin. Oncol. 30 (2012) 372-379. doi:10.1200/JCO.2011.36.9215.

[73] S. Rottenberg, J.E. Jaspers, A. Kersbergen, E. van der Burg, A.O.H. Nygren, S.A.L. Zander, P.W.B. Derksen, M. de Bruin, J. Zevenhoven, A. Lau, R. Boulter, A. Cranston, M.J. O’Connor, N.M.B. Martin, P. Borst, J. Jonkers, High sensitivity of BRCA1-deficient mammary tumors to the PARP inhibitor AZD2281 alone and in combination with platinum drugs, Proc. Natl. Acad. Sci. 105 (2008) 17079-17084. doi:10.1073/pnas.0806092105.

[74] J. Murai, S.N. Huang, B.B. Das, T.S. Dexheimer, S. Takeda, Y. Pommier, Tyrosyl-DNA phosphodiesterase 1 (TDP1) repairs DNA damage induced by topoisomerases I and II and base alkylation in vertebrate cells, J. Biol. Chem. 287 (2012) 12848-12857. doi:10.1074/jbc.M111.333963.

[75] J. Murai, Y. Zhang, J. Morris, J. Ji, S. Takeda, J.H. Doroshow, Y. Pommier, Rationale for poly(ADP-ribose) polymerase (PARP) inhibitors in combination therapy with 
camptothecins or temozolomide based on PARP trapping versus catalytic inhibition, J. Pharmacol. Exp. Ther. 349 (2014) 408-416. doi:10.1124/jpet.113.210146.

[76] I. Lohse, A. Borgida, P. Cao, M. Cheung, M. Pintilie, T. Bianco, S. Holter, E. Ibrahimov, R. Kumareswaran, R.G. Bristow, M.-S. Tsao, S. Gallinger, D.W. Hedley, BRCA1 and BRCA2 mutations sensitize to chemotherapy in patient-derived pancreatic cancer xenografts, Br. J. Cancer. 113 (2015) 425-432. doi:10.1038/bjc.2015.220.

[77] J.L. Lesnock, K.M. Darcy, C. Tian, J.A. Deloia, M.M. Thrall, C. Zahn, D.K. Armstrong, M.J. Birrer, T.C. Krivak, BRCA1 expression and improved survival in ovarian cancer patients treated with intraperitoneal cisplatin and paclitaxel: a Gynecologic Oncology Group Study, Br. J. Cancer. 108 (2013) 1231-1237. doi:10.1038/bjc.2013.70.

[78] O.A. Stefansson, A. Villanueva, A. Vidal, L. Martí, M. Esteller, BRCA1 epigenetic inactivation predicts sensitivity to platinum-based chemotherapy in breast and ovarian cancer, Epigenetics. 7 (2012) 1225-1229. doi:10.4161/epi.22561.

[79] N.C. Turner, A.N.J. Tutt, Platinum chemotherapy for BRCA1-related breast cancer: do we need more evidence?, Breast Cancer Res. BCR. 14 (2012) 115. doi:10.1186/bcr3332.

[80] T. Byrski, J. Gronwald, T. Huzarski, E. Grzybowska, M. Budryk, M. Stawicka, T. Mierzwa, M. Szwiec, R. Wisniowski, M. Siolek, R. Dent, J. Lubinski, S. Narod, Pathologic complete response rates in young women with BRCA1-positive breast cancers after neoadjuvant chemotherapy, J. Clin. Oncol. Off. J. Am. Soc. Clin. Oncol. 28 (2010) 375379. doi:10.1200/JCO.2008.20.7019.

[81] T. Byrski, R. Dent, P. Blecharz, M. Foszczynska-Kloda, J. Gronwald, T. Huzarski, C. Cybulski, E. Marczyk, R. Chrzan, A. Eisen, J. Lubinski, S.A. Narod, Results of a phase II open-label, non-randomized trial of cisplatin chemotherapy in patients with BRCA1- 
positive metastatic breast cancer, Breast Cancer Res. BCR. 14 (2012) R110. doi:10.1186/bcr3231.

[82] K.W. Caestecker, G.R. Van de Walle, The role of BRCA1 in DNA double-strand repair: past and present, Exp. Cell Res. 319 (2013) 575-587. doi:10.1016/j.yexcr.2012.11.013.

[83] L.S. Raut, Novel formulation of cytarabine and daunorubicin: A new hope in AML treatment, South Asian J. Cancer. 4 (2015) 38-40. doi:10.4103/2278-330X.149950. 